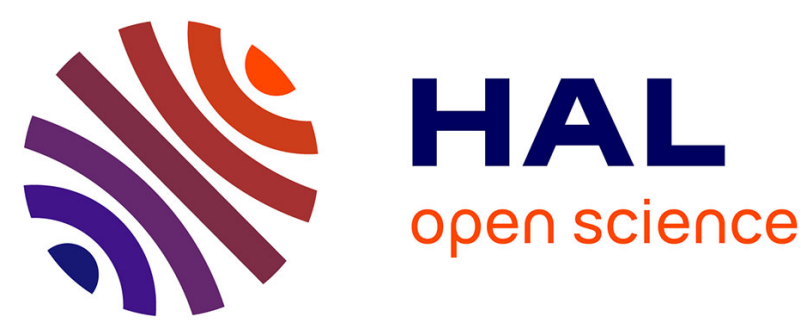

\title{
UX-FFE Model: An Experimentation of a new innovation process dedicated to a mature industrial company
}

\author{
Adrien Lecossier, Marc Pallot
}

\section{- To cite this version:}

Adrien Lecossier, Marc Pallot. UX-FFE Model: An Experimentation of a new innovation process dedicated to a mature industrial company. 23rd ICE/ITMC, Jun 2017, MADEIRA ISLAND, Portugal. pp.7. hal-01697590

\author{
HAL Id: hal-01697590 \\ https://hal.science/hal-01697590
}

Submitted on 31 Jan 2018

HAL is a multi-disciplinary open access archive for the deposit and dissemination of scientific research documents, whether they are published or not. The documents may come from teaching and research institutions in France or abroad, or from public or private research centers.
L'archive ouverte pluridisciplinaire HAL, est destinée au dépôt et à la diffusion de documents scientifiques de niveau recherche, publiés ou non, émanant des établissements d'enseignement et de recherche français ou étrangers, des laboratoires publics ou privés. 


\title{
UX-FFE Model: An Experimentation of a new innovation process dedicated to a mature industrial
} company

\author{
Adrien Lecossier* ; Marc Pallot \\ Arts et Métiers ParisTech, LAMPA. \\ 2, Bd du Ronceray, 49000 Angers, France \\ \{Firstname.lastname\}@ensam.eu
}

\begin{abstract}
*Main contact
Abstract: Most of mature companies, operating through a certain form of repeat business in producing incremental innovations, have lost their ability to conduct radical or breakthrough innovations. While this is not necessarily a bad strategy for short-term sustainability, this is more questionable for future growth and long-term sustainability. Hence, we present in this paper a new innovation model, named UX-FFE because it combines both User eXperience and Fuzzy Front-End approaches. It is intended to tackle economical and social challenges of a successful innovation process. Beyond the systemic processes, like the FFE, addressing the economic stake of a company, our model includes an UX-based process in order to address also the social stake. Then, we explain how this new innovation model was concretely implemented, through the use of several techniques and tools, within a mature industrial company. Finally, we unveil the results of this innovation process experiment for evaluating its potential to overcome both economical and social challenges.
\end{abstract}

Keywords-innovation; fuzzy-front-ends; user experience; experience design; model; experiment

\section{INTRODUCTION}

While companies grow, they tend to operate as a repeat business-based routine. Therefore, they become less open to new ideas and the adaptability of their processes decrease [1] . On the one hand, their constantly refined processes enable the development of high-quality products profiting from the existing product portfolio. Moreover, the industrial culture of rigidified processes limits their capability to deal with disruptive ideas [2], that is also due to the emergence of the syndrome of the "sclerosing bureaucracy" [3]. A recent study framed problems for radical innovation and concluded that in context of radical innovation, companies need to have the ability to experiment new ideas in parallel of routines process, for search, select and implement them under very different conditions [4].

Our case study is carried out in the context of a company dealing with routines processes only. Centenary, the company SOURIAU ESTERLINE is world leader in the business area of connectors for harsh environments. It employs nearly $4 \mathrm{k}$ employees on 5 continents. This empirical study took place on the industrial site of SOURIAU SARTHE (FRANCE), which employs 850 persons. This mature company wants to overcome the following two major challenges to ensure its prosperity, namely: the economic stake and the social stake. For the first challenge, it consists in re-introducing a good capability to conduct radical innovations that could ensure future sustainability and growth. As for the second challenge, it consists in introducing a new capability to satisfy employees and attract new ones by avoiding the phenomenon of sclerosing bureaucracy. In fact, the company wants to find the recipe enabling the creation and validation of radical innovation concepts while responding to social issues. In other words, the creation and validation of new innovative concepts useful for the company future growth must also allow employees to live a social and human experience that improves their perception of work interest. To answer this problem, we propose to experiment a new model named User eXperience (UX) Fuzzy Front Ends (FFE) model. It is based on existing methodologies and techniques. Our objective is to show that within its perimeter, using a UX-FFE model implemented through wellselected methodologies and processes, allows simultaneously to respond to the economic and social stakes of a mature industrial company.

In this paper, we introduce, using a deductive logic, the UX-FFE model. It begins with a brief review of the systemic means responding to the economical and social stakes. We also present our used research approach in order to experiment this model in an industrial environment. Then, we focus on the experiment of the "Strategy" macro-stage that is the first of the 3 macro-stages of the UX FFE model (Fig. 2). Finally, we conclude in unveiling the employees' adoption of the implemented UX-FEE model through their strong willingness to contribute and high level of engagement in this innovative process.

\section{RELATED THEORIES AND MODEL DEDUCTION}

\section{A. Processes for radical innovation at the project level}

The first goal of our model, at the project level, is to allow and engage employees to create and validate innovative concepts exhibiting a real economic value. 
Several scholars demonstrated that the FFE innovation model properly supports the creation and validation of innovative concepts in mature companies while combining both the economic aspect and systemic point of view [5], [6], [7]. In fact, the FFE model is the stage "zero" of a new product development process (NPDP) [8]. It is the stage where many uncertainties subsist creating the symptom called "fuzziness". Uncertainties are various and concern customers, technological and competition [9]. The main role of the FFE model is to improve the NPDP success by reducing uncertainties in advance.

Historically, the FFE model includes 5 steps, namely: (1) Opportunity Identification, (2) Opportunity Analysis, (3) Idea Genesis, (4) Idea Selection, and (5) Concept \& Technology Development (Fig. 1).

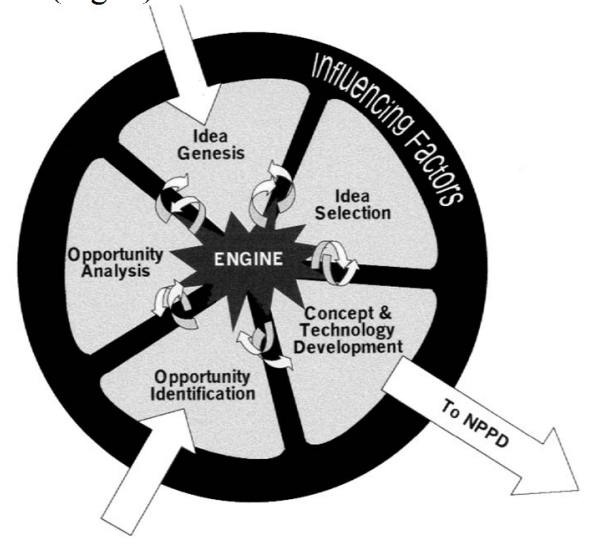

Fig. 1. The New Concept Development Model [3]

Such a FFE model has since been supplemented and modified several times by several other scholars [10], [11], [12]. A new step called "Concept Selection" had also been added in order to separate the step "Concept \& Technology Development" in two parts. In our model we retain the version that orders the FFE in 3 macro-stages [13], namely: (1) identification of opportunity, (2) idea management, and (3) concept development.

In order to be more precise and avoid confusion between FFE steps and these 3 macro-stages, we respectively call these 3 macro-stages: "Strategy", "Ideation", and "Validation" (Fig. 2). The 6 FFE steps are then positioned inside the macrostages.

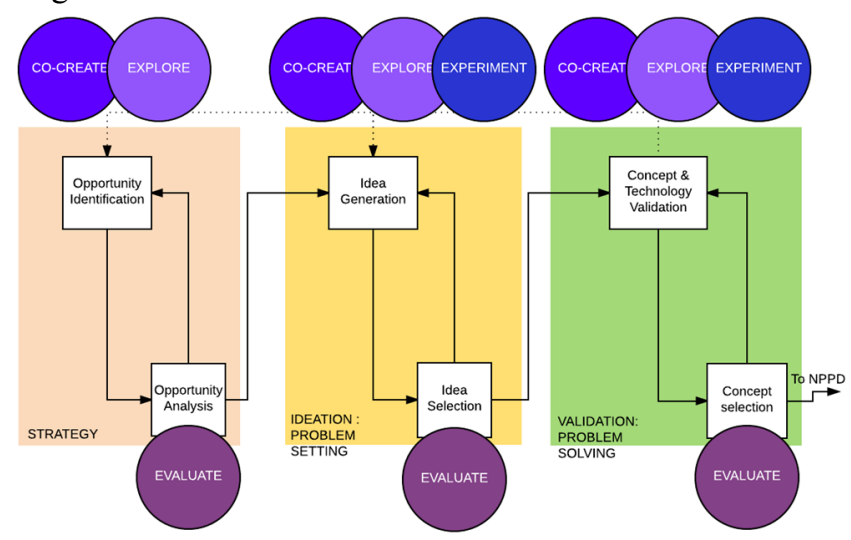

Fig. 2. FFE Model used inside our global systemic vision model
The second goal of our extended FFE model is to allow employees to get into social and human experiences when they are creating and validating innovative concepts at the earlier stage. In other words, our model imposes that each of the 6 steps of the FFE model allows creating both an economic and social value. The later is generated by employees' social and human experience gained along this innovation process.

It is almost impossible to identify a consensus, between researchers and practitioners, on what UX is [14]. For example, Law et al. claim that: "UX is dynamic, context dependent, and subjective." [15]. According to Pallot and Pawar, UX is multi-dimensional and multi-facetted due to the many different types of experience, including social and empathical experiences, that users can live when using a product [16]. They have decomposed each type of experience in elements and properties that allow evaluating its quality. They assume that UX quality, often named Quality of Experience (QoE), is the sum of the quality of each constitutive type of experience. Nevertheless, there also exists the following standardized description of UX provided by the International Standard Organization [17]: "User Experience is a person's perceptions and responses that result from the use or anticipated use of a product, system or service". The ISO description presents UX as a combination of all users' emotions, beliefs, preferences, perceptions, physical and psychological responses, behaviors and accomplishments that occur before, during and after the use of product, system or service. Furthermore, it is said that the type of product, system, service, user profile and the context of use are factors that influence user experience.

Therefore, our model introduces the Iterative eXperience Design Process (IXDP) because it supports social and human experiences [16]; hence, tackling the second challenge (Fig. 3 ). We use this process in order to represent the cognitive and operational tasks that occur during the 6 steps of the FFE as shown in Fig. 2.

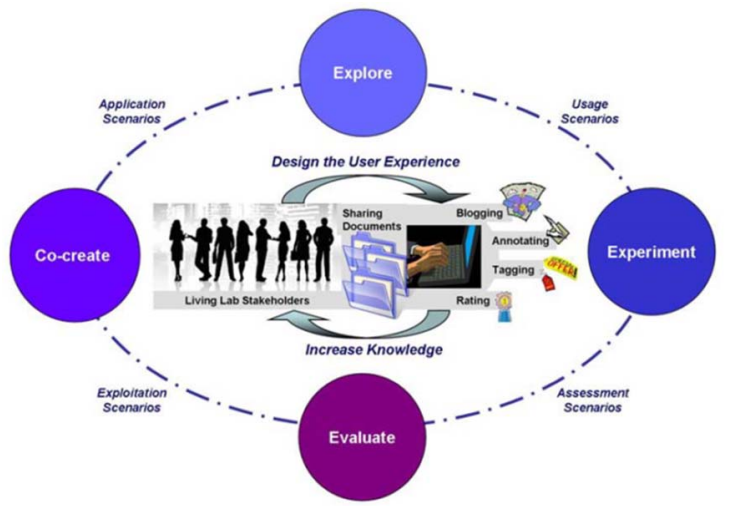

Fig. 3. The Living Lab Iterative Experiential Design Process [16]

By definition, from a systemic point of view, our model proposes an integration of models coming from different scientific domains. This approach makes possible to better represent the operational and cognitive behavior aspects of the FFE model. It also allows to better respond to social and economic stakes. The TABLE I synthetizes the rational aspirations and advantages of the UX-FFE model. 
TABLE I-Rational aspiration of the UX-FFE model

\begin{tabular}{|c|c|c|c|}
\hline & FFE & IXDP & UX-FFE \\
\hline $\begin{array}{c}\text { Radical } \\
\text { innovation dvt }\end{array}$ & $* * *$ & $*$ & $* * *$ \\
\hline $\begin{array}{c}\text { Radical } \\
\text { innovation adpt }\end{array}$ & $* *$ & $* *$ & $* * *$ \\
\hline $\begin{array}{c}\text { Radical } \\
\text { innovation } \\
\text { guidelines }\end{array}$ & $* *$ & $*$ & $* * * *$ \\
\hline $\begin{array}{l}\text { Innovation } \\
\text { process } \\
\text { productivity }\end{array}$ & $* *$ & $* *$ & $* * * *$ \\
\hline Social openness & - & $* *$ & $* * *$ \\
\hline $\begin{array}{l}\text { Sens of } \\
\text { community } \\
\text { during the } \\
\text { innovation } \\
\text { process }\end{array}$ & - & $* *$ & $* * *$ \\
\hline Engagement & - & $*$ & $* * * *$ \\
\hline $\begin{array}{l}\text { Relationship } \\
\text { enhancement }\end{array}$ & - & $* *$ & $* * *$ \\
\hline $\begin{array}{c}\text { Feeling to be } \\
\text { useful }\end{array}$ & - & $* *$ & $* * *$ \\
\hline
\end{tabular}

The TABLE I presents a comparison of 3 models. The rating is based on some criteria used in order to evaluate the model capability to answer to the social and economical objectives of our research works. The TABLE I shows for example that social criteria which are not considered in the FFE model are well integrated in the UX-FFE model.

From an operative point of view, it is also necessary to identify tools potentially overcoming the economic and social challenges that our model has to tackle.

\section{B. Operative methodologies and technics for radical innovation at the project level}

The literature review helped us identifying many tools that support each of the steps of the FFE process [6]. Not all have been evaluated on the dual challenge imposed by our model. Indeed, some methods favor the social experience without worrying so much about the economical outcome that they induce. For example, several creativity techniques used during the Idea Generation step provide some sort of fun among participants and increase the group dynamics. But in fact, they finally produce only ideas poorly innovative or not adapted to the economical goal. This means that the ability of a tool to promote the successful completion of one or more steps of the FFE has been neglected; thus, neglecting the capability of FFE using this tool to create and validate innovative concepts. In contrast, there are also tools that focus only on the economic outcome without worrying about the social and human experience, even if its quality can be very low.

Therefore, in order to avoid this discrepancy, our model uses tools that allow the expected economical outcome and a social and human experience for their users. Regarding the Strategy macro-stage, there are tools, such as: technological monitoring, analysis of trends, identification of future generations of products, market analysis, competitiveness analysis, and scanning of the external and internal environment allowing both to explore innovation strategies and evaluate their potential [18], [6]. However, there are fewer tools allowing co-creating at this stage. One technique we identified and decided to use in our model is the "Strategy workshop" (eg. World Café) because it answers to the dual challenge. In fact, strategy workshop allows to its participants to get into a social and human experiences; and also ensures an economical outcome [19]. It consists in facilitating individual growth by improving the collective understanding [20]. This kind of workshop also mobilizes the mainstream staff that ensures the emergence of radical innovation [21]. Finally, during a strategy workshop people co-create, explore and evaluate innovation opportunities.

As for the Ideation and Validation macro-stages, our model implements the Radical Innovation Design (RID) process because it gives operational tasks in order to accomplish the 4 FFE steps [22], [23]. The RID process itself consists of two major stages, respectively called "Problem Setting" and" Problem Solving". Each of these stages lists a number of tasks to be carried out in order to provide the necessary proof of concept validating its innovativeness. In view of the results, we consider that the RID process supports our extended FFE model responding to its economic stake during the Ideation and Validation macro-stages (Fig. 2). However, this process is not the ideal tool to overcome the social challenge included in our model even if it assumed that people co-create, explore, experiment and evaluate their ideas and concepts. Moreover, it does not provide a precise methodology to accomplish each of its tasks. We therefore use complementary methods to ensure that our model responds well to its economical and social stakes during the Ideation and Validation macro-stages.

As for tooling the Ideation macro-stage, we decided to use the Knowledge Concept Proposition (KCP) creative methodology [24]. This method has two advantages in correlation with the two above-mentioned stakes of our model. The first one is that $\mathrm{KCP}$ is based on collaborative work fostering the participants' social and human experience. The second one is that KCP allows a dual creative expansion in a continuous or discontinuous way [25]. In other words, this means that this methodology can guide the creation of ideas accordingly to a precise objective. Thus, innovative ideas of different degrees emerge, depending on the initial objective coming from the "Strategy" macro-stage. To synthesize their ideas, participants use the format of the identity of an object. This formalism synthesizes the ideas into four parts, namely: (1) Values and Uses, (2) Sales Ecosystem and Business Model, (3) Functional Description, and (4) Nature of Performance. In addition, the KCP methodology, used during the Ideation macro-stage, follows the operative and cognitive path of the iterative XD process (Fig. 2). By definition, it allows participants to experience social and human aspects, 
while ensuring an economic outcome. The idea selection step uses the collective intelligence of the team members that construct selection criteria for evaluating their ideas. This practice promotes the social and human experience [26].

Regarding the Validation macro-stage, we decided to use a selection grid "SAPIGE" (System of selection and support of generic innovation projects) derived from the RID process [27]. This grid is a tool that can be used to drive and evaluate an innovation project. Using it allows to know the dimensions on which profitability and feasibility proofs have to be validated in order to consolidate the innovative concept and then answer the economical stake [27], [28].

Many tools have been used during the experimentation. This is why, in order to improve readability we propose the TABLE II summarizing their use inside the UX-FFE model.

TABLE II - Synthesis of the tools used in the UX-FFE model

\begin{tabular}{|c|c|c|c|c|c|c|}
\hline$\rightarrow$ Stages & \multicolumn{2}{|c|}{ STRATEGY } & \multicolumn{2}{|c|}{ IDEATION } & \multicolumn{2}{|c|}{ VALIDATION } \\
\hline $\begin{array}{c}\rightarrow \text { Steps } \\
\downarrow \text { Activities }\end{array}$ & OI & OA & IG & IS & CTV & CS \\
\hline Co-create & & Wksp & $\mathrm{KCP}$ & & & \\
\hline Explore & Qst & & $\mathrm{KCP}$ & RID & RID & RID \\
\hline Experiment & & & $\begin{array}{c}\text { Drawin } \\
\mathrm{g}\end{array}$ & & $\begin{array}{l}\text { Model } \\
\text { / Proto }\end{array}$ & \\
\hline Evaluate & $\begin{array}{l}\text { Trd } \\
\text { Anls }\end{array}$ & $\begin{array}{c}\text { Col } \\
\text { choice }\end{array}$ & $\begin{array}{l}\text { ID objt } \\
\text { anls }\end{array}$ & $\begin{array}{l}\text { Col } \\
\text { choice }\end{array}$ & Sapige & Sapige \\
\hline
\end{tabular}

(Qst: Questionnaire; Trd Anls: Trend Analysis; Wskp: Workshop; ID objt anls: Identity of object analysis; Col choice: collective choice)

The TABLE II presents for example that the UX-FFE model implements the Workshop method in order to realize the Cocreation activity during the Opportunity Analysis step of the Strategy macro-stage.

\section{RESEARCH APPROACH}

\section{A. Strategy macro-stage procedure}

a) A survey for identifying opportunities: A preliminary survey was conducted on innovation topics. Overall, 64 employees, having a profile ranging from the technical to the marketing and R \& D manager, responded to this survey. The results of the survey show that $95 \%$ of respondents want to innovate more and $98 \%$ do believe that the company must innovate in order to survive. However, $61 \%$ of them think they innovate in their actual work. Without distinction, $80 \%$ of respondents question the organization's ability to innovate. They describe the organizational structure as "aging", "too rigid" because "doing too much administration". Out of the $80 \%$ of employees who challenge the organization, $61 \%$ think it should be changed and $19 \%$ ask for a new one. The results of this preliminary investigation are the outcomes of an internal monitoring process. They highlight a certain weariness of the employees. These data were synthesized in the form of posters. These posters constituted the basisreference material for the strategy workshop.

b) A collective workshop for opportunities analysis: Employees that responded to this internal survey were invited to participate to the strategy workshop. Overall, 40 employees contributed, representing $64 \%$ of the participants of the preliminary investigation (Fig. 4).

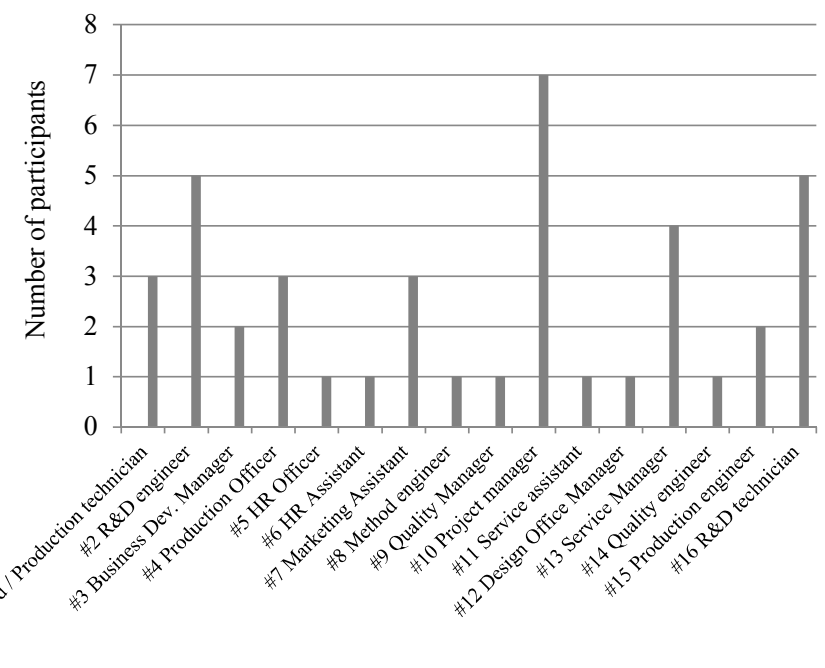

Fig. 4. Workshop participants' typologies and size

The 40 participants were divided into 4 groups of 10 persons. Each group was inter-disciplinary and included employees of several hierarchical levels.

The workshop lasted $1 \mathrm{~h} 40$ and was cut in 3 rounds of 30 minutes and 1 round of 10 minutes. Academic experts in innovation presented the results of the internal survey during the first round of 30 minutes. This survey presentation was divided in 4 parts. Each of these parts corresponded to a poster that was then discussed by the participants during the second and third round. The second round consisted to collectively analyze the posters. The groups were due, in a period of 30 minutes, to come with an operational strategic topic contributing to solve the problem implied by the results of the internal investigation.

In each group, one member was freely designated as 'table leader'. The third round started by table-members' rotation. Only table leaders remain on their respective seat in order to explain the advancement of each table discussion to the new members. The goal was then to continue the previous exercise and synthesize the discussion. Each group was due to also deliver a presentation of its operational strategic topic during the fourth round. In this round, the table leaders presented the strategic goals discussed on their tables. All participants were then invited to vote for the topic they preferred and would like to further develop in the up-coming events.

The number of persons wishing to participate to an upcoming innovation project was collected at the end of the workshop; this was corresponding to the end of the Strategy macro-stage. Moreover, at the launch of the innovative projects, corresponding to the starting of the Ideation macro- 
stage, we gathered the number of employees who still wanted to participate. We also collected the elapse time between the date of the workshop and the date of the official launch of the innovative projects addressing the resulting topics. Indeed, these collected data inform about the dissemination of the topics co-created during the workshop. A high dissemination rate, for a radical innovation topic, indicates that the economic stake is mostly respected.

To assess the participants' social experience, a satisfaction questionnaire was distributed at the end of the workshop. Respondents had to assess whether their level of participation during the workshop has been rather active than inactive. This evaluation is intended to verify whether the Opportunities Analysis step carried out in the form of a workshop promotes the openness of each participant. Thus the combination of dissemination data with the evaluation of social experience allow to validate whether the workshop technique meets the two challenges required by our model during the stage of opportunities analysis.

\section{B. Ideation macro-stage procedure}

This stage begins with the launch of an innovative project. The subject of this project corresponds to one of the topics cocreated during the strategy workshop. Then, participants who voted for this topic were invited to contribute to the corresponding innovative project and to become group members. According to our model, the Ideation stage is guided by the RID process and begins with idea generation step (Fig. 2). For the innovative project, which we study in this paper, the KCP method was used to fill-in the "Problem Setting" tasks. It took place in a dedicated meeting room, in 3 sessions of 2 hours separated by one week. The goal was for a group member to propose ideas that fill-in the tasks of the "Problem Setting" using the format of the identity of an object. Once presented, group members were invited to vote for ideas according to defined criteria. The procedure was that participants, led by our intervention during these 3 sessions, worked synchronously [29] at the same time in the same place.

\section{Validation macro-stage procedure}

This phase is the continuation of the Ideation macro-stage. According to our model, group members started to work on solving the tasks of "Problem Solving" by exploring, cocreating, experimenting and evaluating the innovative concept (Fig. 2). The instruction required that when the group deemed it necessary, the top management team using the SAPIGE grid evaluated the concept. Then, the top management team decided whether the concept could be transferred to the development stage or not. The procedure was that group members, led by our intervention, worked synchronously and asynchronously during the Validation macro-stage.

\section{FINDINGS}

\section{A. Economic issue from the Strategy macro-stage}

At the end of the workshop, table leaders presented 4 strategic topics to all participants. Then, all participants were invited to vote for the topic they would like to contribute. A total of 36 votes were issued and distributed within the 4 strategic topics (Fig. 5). The results show that $90 \%$ of participants desire to be involved in innovative projects. More precisely, $15 \%$ of participants desired to contribute to the topics A and C, $25 \%$ to the topics B and $35 \%$ to the topic D (Fig. 5).

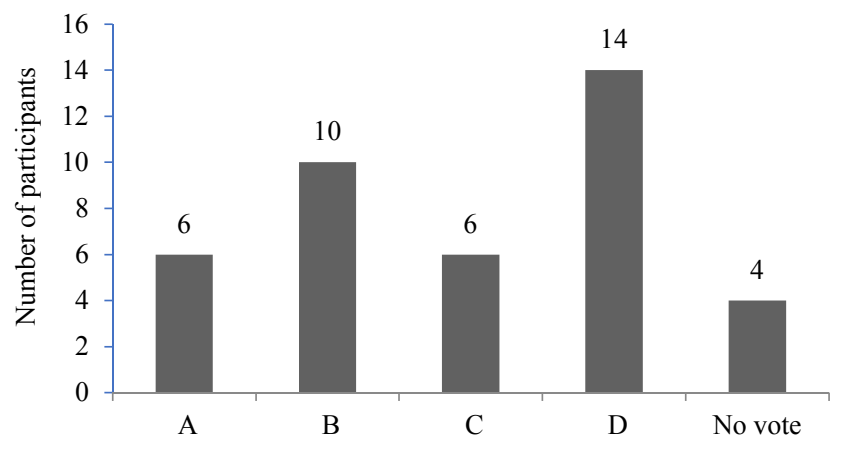

Fig. 5. Distribution of participants' votes at the end of the workshop $(\mathrm{N}=36)$

When starting the radical innovative projects, we gathered the number of employees who still wanted to participate. Except for the proposition $\mathrm{C}$, which was canceled because it looked as a mix of other propositions, results show that the rate of involvement willingness in projects that address topics co-created during the workshop varies between $83 \%$ and $93 \%$ (Fig. 6). On average, participants of the workshop were willing to participate to $90 \%$ of innovative projects that address the strategic topics identified during the workshop. This value represents a real commitment and strong engagement of employees.

desiring participate in innovative projects at the end of the workshop

desiring participate in innovative projects at the project launch

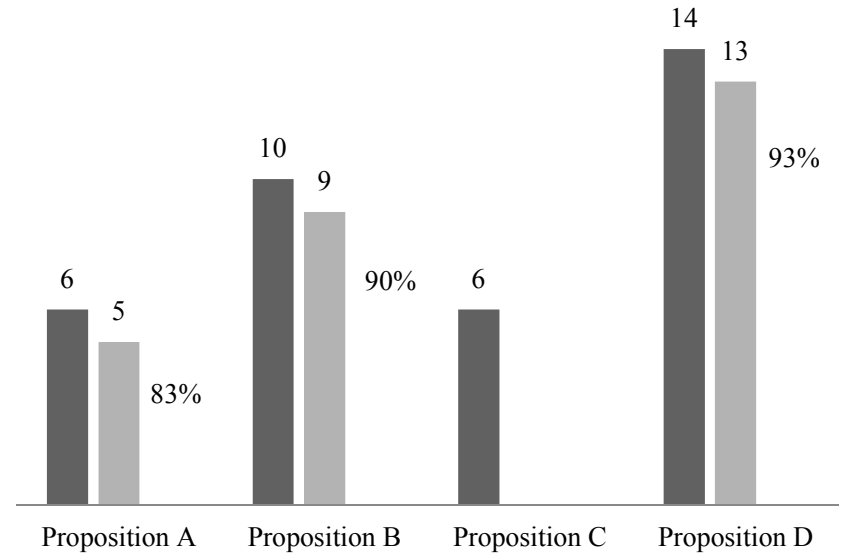

Fig. 6. Commitment of participants for the innovative projects they had chosen

Moreover, our results show that this commitment rate, which amounts to $90 \%$, is not eroded over time. Indeed, projects $\mathrm{A}, \mathrm{B}$ and $\mathrm{D}$ were launched respectively 15, 380 and 180 days after the workshop. 


\section{B. Social issue from the Strategy macro-stage}

When leaving the workshop, participants were free to complete the satisfaction questionnaire. In total, 34 employees ( $85 \%$ of participants) responded to the survey (Fig. 7).
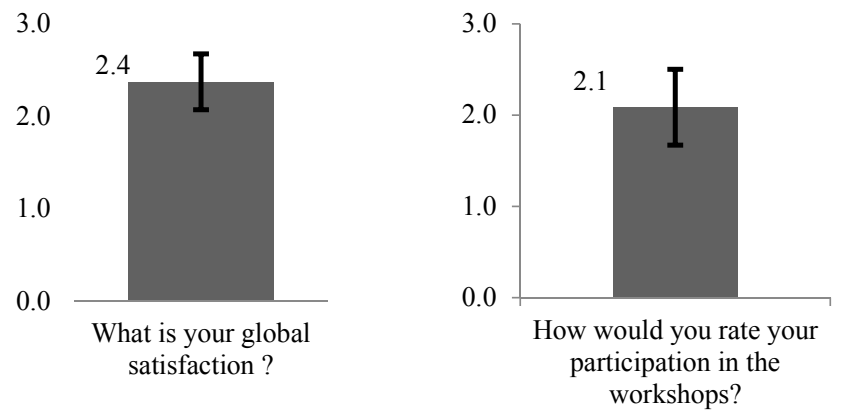

Fig. 7. Results of the satisfaction questionnaire $(\mathrm{N}=34)$

The results show that employees felt they were actively participating during the workshop. Furthermore, they expressed a high global satisfaction (Fig. 7). When asked if they have comments to make on the workshop they answer: "Dynamic and interesting", "Great!", "Good" or "To be done once a month". These comments are assumed as reflecting the hedonic quality of the used technique during the workshop and confirm the high global satisfaction result. They also validate that the strategy workshop allows participants to experiment a part of social experience during the Opportunities Analysis step of the Strategy macro-stage (Fig. 2).

In order to better understand why some participants, felt that they were more active than others, we asked them what could be improved (Fig. 8).

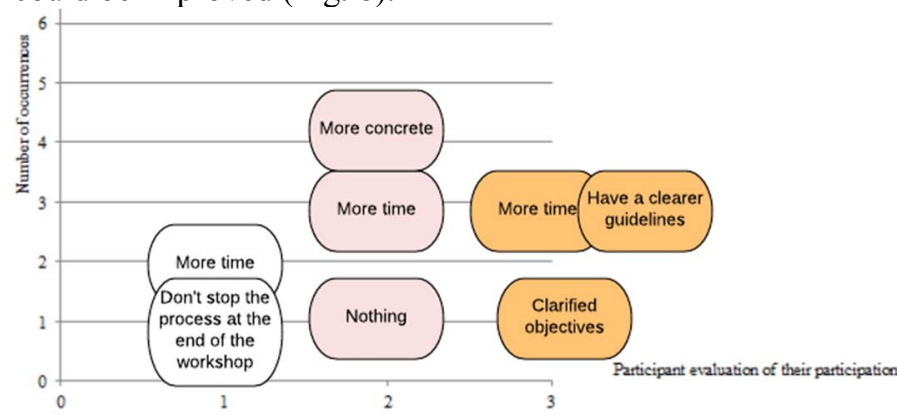

Fig. 8. Grouping of answers in trends and positioning according to their number of occurrences

The results show that all participants would have liked to spend a longer period of time. Participants, who rated themselves as very active, said they lacked a real leader and more concrete objectives.

\section{Crossing of the Economic and Social issue from the Strategy macro-stage}

The results show that social elements, experienced by the participants during the workshop to complete the Opportunity Analysis step, have an influence on the economic outcome. Indeed, the economic outcome is firstly linked with difficulties of radical innovation topics introduction in strategy and organization of mature companies. It can be improved by allowing employees to get into social and human experiences from the Strategy stage of the UX-FFE model (Fig. 2).

For example, results show that participants who have valued themselves as 'low active' during the workshop are, on average, less inclined to participate to induced innovative projects (Fig. 9).

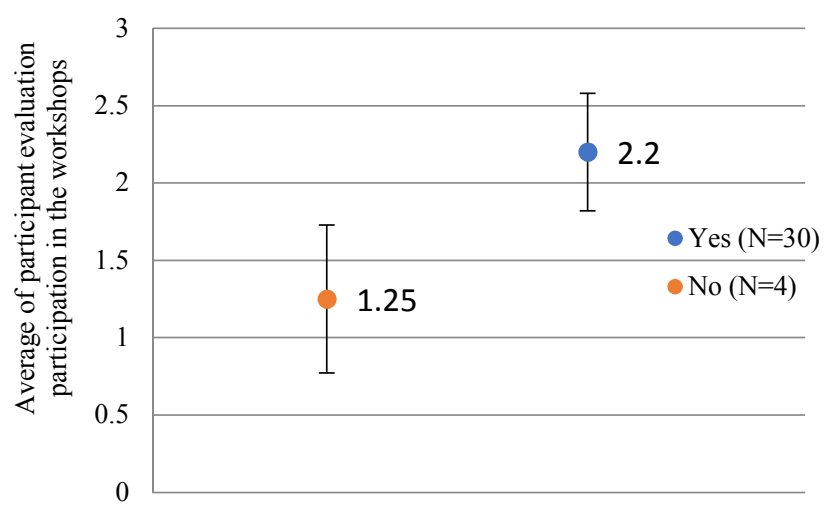

Fig. 9. Influence of the feeling of having participated in the opportunities analysis step on the desire to participate in a future innovation project

\section{CONCLUSION AND FUTURE WORK}

We introduced a new model called UX-FFE taking into account both economic and social aspects. This ambition makes our model more complex in terms of structure. Indeed, beyond the systemic processes like the FFE that fill the economic stake of a mature company, our model integrates an UX process in order to answer the social stake.

We saw that the implemented UX-FFE model proposes a sequence of 3 stages. Firstly, the Strategy stage, during which opportunities are identified and analyzed. Secondly, comes the Ideation stage consisting of steps of creation and selection of ideas. Thirdly, the Validation stage occurs for selecting and validating innovative concepts that are then transferred to the development process. In each of these stages, methodologies are chosen in order to ensure the best UX for employees who realize 4 main activities: co-creation, exploration, experimentation and evaluation.

In this paper, we presented an experiment of the Opportunities Analysis step within the Strategy stage. We decided to use a strategic workshop methodology to allow employees to cocreate, explore and evaluate radical innovation opportunities. Results reveal that the social experience felt by employees, who collectively worked in the opportunities analysis stage, is very much appreciated and really engaging. As a proof of concept, an average of $90 \%$ of employees, involved in the opportunities analysis stage, have accepted to participate to the Ideation stage even after a long period of time that did not erode their willingness to contribute and their strong engagement in this innovation process.

\section{ACKNOWLEDGMENT}

Authors wish to acknowledge the openness and willingness of the company SOURIAU ESTERLINE to explore new challenges and fund this study. 


\section{REFERENCES}

[1] C. S. Koberg, D. R. Detienne, and K. A. Heppard, "An empirical test of environmental, organizational, and process factors affecting incremental and radical innovation," J. High Technol. Manag. Res., vol. 14, no. 1, pp. 21-45, 2003.

[2] R. Leifer, G. Colarelli O 'connor, M. Rice, and G. Colarelli O 'connoer, "Implementing Radical Innovation in Mature Firms: The Role of Hubs," Source Acad. Manag. Exec., vol. 15, no. 3, pp. 102113, 2001.

[3] J. M. Birkinshaw, G. Hamel, and M. J. Mol, "Management innovation," Acad. Manag. Rev., vol. 33, no. 4, pp. 825-845, 2008.

[4] J. Bessant, C. ??berg, and A. Trifilova, "Framing problems in radical innovation," Ind. Mark. Manag., vol. 43, no. 8, pp. 12841292,2014

[5] P. Koen, G. Ajamian, R. Burkart, A. Clamen, J. Davidson, R. D'Amore, C. Elkins, K. Herald, M. Incorvia, A. Johnson, R. Karol, R. Seibert, A. Slavejkov, and K. Wagner, "Providing Clarity and a Common Language To the 'Fuzzy Front End.,"” Res. Technol. Manag., vol. 44, no. 2, pp. 46-55, 2001.

[6] V. Sellman, "Learnings from the front end of radical product innovation in mature firms A descriptive analysis of how BillerudKorsnäs can manage the front end of radical product innovation in the Management and Economics of Innovation Programme," 2016.

[7] C. Stüer, S. Hüsing, and S. Biala, "How to create and sustain an open and radical innovation capability in the fuzzy front end: The case of Vodafone Group R\&D Germany and selected ongoing radical innovation projects," Int. J. Prod. Dev., vol. 11, no. 3-4, pp. 196-219, 2010.

[8] A. Khurana and S. R. Rosenthal, "Towards Holistic Front Ends In New Product Development," Journal of Product Innovation ..., vol. 15, no. 1. pp. 57-74, 1998.

[9] J. Kim and D. Wilemon, "Focusing the fuzzy front-end in new product development," $R \& D$ Manag., vol. 32, no. 4, pp. 269-279, 2002.

[10] U. De Brentani and S. E. Reid, "The fuzzy front-end of discontinuous innovation: Insights for research and management," $J$. Prod. Innov. Manag., vol. 29, no. 1, pp. 70-87, 2012.

[11] S. E. Reid and U. De Brentani, "The fuzzy front end of new product development for discontinuous innovations: A theoretical model," $J$. Prod. Innov. Manag., vol. 21, no. 3, pp. 170-184, 2004.

[12] Q. Zhang and W. J. Doll, "The fuzzy front end and success of new product development: a causal model," Eur. J. Innov. Manag., vol. 4, no. 2, pp. 95-112, 2001.

[13] U. Dornberger and A. Suvelza, "Managing the Fuzzy Front-End of Innovation," pp. 1-225, 2012.

[14] D. L. Scapin, B. Senach, B. Trousse, and M. Pallot, "User experience: Buzzword or new paradigm?," ACHI 2012 - 5th Int.
Conf. Adv. Comput. Interact., no. January, pp. 336-341, 2012.

[15] E. L.-C. Law, V. Roto, M. Hassenzahl, A. P. O. S. Vermeeren, and J. Kort, "Understanding, scoping and defining user experience," Proc. 27th Int. Conf. Hum. factors Comput. Syst. - CHI 09, no. April 2016, p. 719, 2009.

[16] M. Pallot and K. Pawar, "A holistic model of user experience for living lab experiential design," 2012 18th Int. ICE Conf. Eng. Technol. Innov., pp. 1-15, 2012.

[17] ISO FDIS 9241-210, "Ergonomics of human system interaction Part 210: Human-centered design for interactive systems (formerly known as 13407)," 2009.

[18] C. Bouchard, H. Christofol, and D. Lim, "Integration of Stylistics and Uses: Trends in the Innovation Process," Innov. Eng. Power Intang. Networks, no. February, pp. 175-195, 2013.

[19] K. a. Burke, T. J. Greenbowe, and J. I. Gelder, "The Multi-Initiative Dissemination Project Workshops: Who Attends Them and How Effective Are They?," J. Chem. Educ., vol. 81, no. 6, p. 897, 2004.

[20] W. L. Chang and S. T. Chen, "The impact of World Caf?? on entrepreneurial strategic planning capability," J. Bus. Res., vol. 68, no. 6, pp. 1283-1290, 2015.

[21] J. Nicholas and B. E. M. Eng, "An Investigation into the Practices and Underlying Factors during the Fuzzy Front End of Radical Innovation," no. April, 2014.

[22] B. Yannou, M. Jankovic, and Y. Leroy, "Empirical Verifications of Some Radical Innovation Design Principles Onto the Quality of Innovative Designs," Iced11, no. August, pp. 1-13, 2011.

[23] B. Yannou, "Which research in design creativity and innovation? Let us not forget the reality of companies," Int. J. Des. Creat. Innov., vol. 1, no. 2, pp. 72-92, 2013.

[24] F. Arnoux and M. Bejean, "Strategies for Building Radical Innovation Potential: Exploring the Role of Collaborative Creative Design Methods," 17th PDMC 2010, pp. 1-20, 2010.

[25] P. Le Masson, A. Hatchuel, and B. Weil, "Design Theory and Collective Creativity: A Theoretical Framework to Evaluate KCP Process," Int. Conf. Eng. Des., pp. 277-288, 2009.

[26] M. Takahashi, K. Nemoto, N. Hayashi, and R. Horita, "The Measurement of Dialogue: From a Case Study of the Workshop Using World Café as a Collective Dialogue Method," J. Inf. Process., vol. 22, no. 1, pp. 88-95, 2014.

[27] B. Zimmer, "Structuration d' un cluster d' innovation : Application aux projets $d$ ' innovation dans une grappe $d$ ' entreprises en gérontechnologie," p. 223, 2012.

[28] B. Zimmer, B. Yannou, and J. Stal- Le Cardinal, "Proposal of radical innovation project selection model based on proofs of value, innovation and concept," in International Design Conference, 2012.

[29] A. Piquet, "Guide pratique du travail collaboratif: Théories, méthodes et outils au service de la collaboration,” p. 80, 2009. 